\title{
Entrevista a Alexandre Coello de la Rosa ${ }^{1}$
}

\author{
Carlos Daniel Paz
}

La presente entrevista, realizada a Alexandre Coello de la Rosa ${ }^{2}$ (UPF/BarcelonaEspaña), en su casa y junto a su familia, fue concretada por medio Skype y tiene una duración, aproximada, de unos cincuenta y cinco (55) minutos en dónde con nuestro querido amigo y colega repasamos algunas cuestiones por demás interesantes tanto en lo que hacen a su formación e investigaciones sobre diversas problemáticas así como a aspectos estrictamente vinculados con el problema central que hemos presentado como propuesta para el presente Dossier.

Esta entrevista se constituye como un espacio de diálogo en el que deseamos manifestar nuestro agradecimiento a nuestro entrevistado así como la paciencia de Gilmar Arruda y su equipo de edición.

Con Alexandre conversamos sobre distintos tópicos que presentamos aquí bajo la forma de preguntas, tal y como se las hicimos llegar y, luego, las respuestas poseen una labor de edición que hace posible la comprensión de las diferencias entre la oralidad y el lenguaje escrito, aunque conservando algunas expresiones propias de la oralidad para, de ese modo, poder recrear mejor el diálogo mantenido. Los trechos que se presentan entrecomillados corresponden a expresiones en las cuáles Alexandre Coello de la Rosa coloca mayor énfasis. Aclaradas estas cuestiones mínimas he aquí las preguntas.

\footnotetext{
1 - Grabación, transcripción, edición y notas: Carlos D. Paz. Formulación de la entrevista: Maria Cristina Bohn Martins y Carlos D. Paz.

${ }^{2}$ Doctor en Historia (2001) por Stony Brook University (NY-USA). Actualmente es Profesor Agregado en el Departamento de Humanidades de la Universitat Pompeu Fabra (UPF-Barcelona / España). Es co-editor de la revista Islas e Imperios, publicación del Grup de Recerca en Imperis, Metrópolis i Societats Extraeuropeas (GRIMSE-UPF) y Coordinador del Master en Estudios de Asia-Pacífico en un Contexto Global (UPF). Cuenta con una prolífica labor de investigación reflejada en numerosos artículos así como en los libros que ha publicado y editado, de los cuáles podemos destacar: El Pregonero de Dios. Diego Martínez, SJ, misionero jesuita del Perú colonial (1543-1626). Valladolid, Universidad de Valladolid, 2010; Escritura, imaginación política y la Compañia de Jesús en América Latina [siglos XVI-XVIII], en colaboración con Teodoro Hampe Martínez [eds.] Barcelona, Edicions Bellaterra, 2011; Jesuitas e Imperios de Ultramar, Siglos XVI-XX, en colaboración con Doris Moreno [eds.] Madrid, Sílex, 2012; Jesuits at the Margins: Missions and Missionaries in the Marianas. London \& New York, Routledge, 2016; Elogio de la Antropología Histórica. Enfoques, métodos y aplicaciones al estudio del poder y del colonialismo, en colaboración con Josep Lluís Mateo Dieste. Zaragoza, Prensas de la Universidad de Zaragoza y Barcelona, Editorial UOC, 2016 y, La Justicia Robada. Corrupción, codicia y bien público en el mundo hispánico (siglos XVII-XX), en colaboración con Martín Rodrigo y Ahlarilla (eds.) Barcelona. Icaria Editorial, 2018.
} 
Pregunta: Como una primera cuestión, y a modo de introducción, deseamos presentarte ante los lectores de Antíteses y para ello te pedimos que realices una breve manifestación sobre tu formación como historiador, tu interés por el accionar de la Compañía de Jesús con especial énfasis sobre tus abordajes sobre Perú y Filipinas- y tus proyectos actuales de investigación.

Respuesta: Comencé con estas cuestiones hace ya bastante tiempo. Mi interés por Perú se dio en los momentos en que cursaba mi Licenciatura en la Universidad de Barcelona (en adelante UB). Hice mi primera asignatura de Etnología Andina con Jesús Contreras que por entonces era Profesor Titular de la UB; él había sido uno de los antropólogos que había ido, en aquella época, con Gonzalo Sanz, con María Jesús Buxó Rey, con Claudio Esteva Fabregat que fue el fundador del Departamento de Antropología de la UB en los años '70-, a Chinchero (Perú). Henrique Urbano, al respecto, siempre decía, en broma claro, "que los de Chincheros eran todos mentirosos" y entonces el caso fue que fueron un grupo de antropólogos para allá y después a raíz de eso comenzaron a hacerse asignaturas, y yo entré ahí y me interesé mucho por el mundo andino y entonces a partir de ahí mi especialidad en Antropología fue la Etnohistoria. Entonces Jesús tiene la culpa de que yo me interesara por el mundo andino.

Después conocí a Neus Escandell Tur que fue la que hizo aquel libro famoso de obrajes que publicó en el Bartolomé de Las Casas ${ }^{3}$ y ella fue la persona que ya una vez que acabé la Licenciatura y terminé mi Maestría en la [Universidad] Autónoma [de Barcelona], me orientó para que fuera a los Estados Unidos; aquí no había posibilidad de acceder a becas. Entonces ella me aconsejó. En ese momento tenía dos opciones, o irme a Michigan o irme a Stony Brook y entonces allí tuve la oportunidad de ser Teacher Assistant. Después trabajé con Brooke Larson, Barbara Weinstein y con Paul Gootenberg. Era un Departamento muy importante en Historia de América Latina, sobre todo en el mundo andino.

Entonces a partir de ahí me interesé por los jesuitas, por todo lo que he ido haciendo, por Perú pero sobre todo, más recientemente, por otros ámbitos geográficos. Pero básicamente mi historia es la historia vocacional de alguien que se ha interesado por la Historia Eclesiástica, que empecé con el mundo andino pero que de alguna manera también lo que me ha interesado es la Historia de la Iglesia. En mi Maestría continué con estos temas, los perfeccioné y los amplié con todo lo que fue mi Doctorado.

Luego, cuando volví aquí a España y conseguí mi plaza en la Universitat Pompeu Fabra (en adelante UPF), como en la UPF había un grupo muy potente de estudios de Asia-Pacífico cambié de área geográfica pero continuando con "mis jesuitas" y tras la pista de ellos me orienté hacia espacios un poco diferentes. Ahora mismo estoy trabajando con cuestiones

\footnotetext{
${ }^{3}$ La obra a la que refiere nuestro entrevistado es Producción y Comercio de Tejidos Coloniales: los obrajes y
} chorrillos del Cuzco, 1570-1820. Centro de Estudios Regionales Andinos, Bartolomé de las Casas, 1997. 
relacionadas con Filipinas pero he trabajado Marianas y fundamentalmente espacios periféricos que son los temas que me interesan más. Periferias concretas del Imperio español, bueno Perú era una periferia en cierto sentido, pues luego Marianas y Filipinas en efecto lo fueron.

Me interesan varias cosas. Me ha interesado no sólo la Historia de la Compañía de Jesús, también he hecho cosas relacionadas con Crónicas de Indias. Sobre todo en particular la obra de Gonzalo Fernández de Oviedo sobre el cual he escrito varias cosas, un par de libros y demás; luego también la Antropología Histórica que es una cuestión que últimamente me ha ido atrapando sobre todo a partir de un libro que publicamos con Josep Lluís Mateo Dieste en Zaragoza. Un trabajo que, además va a publicarse traducido al inglés por Routledge, tiene que ver con este "Elogio" que algunos llaman en Brasil 'Historia Indígena', que en los '70 se llamó Etnohistoria y que nosotros, un poco, por seguir a Verena Stolcke -que fue la que siempre nos empujó a acabar este libro- pues le llamamos Antropología Histórica ${ }^{4}$. Pero bueno, en particular estoy ahora mismo trabajando en cuestiones relacionadas con Filipinas, sobre todo cosas de Historiografía y en trabajos futuros lo que estoy planeando es hacer una historia que tenga que ver con los conflictos jurisdiccionales sobre todo entre Órdenes eclesiásticas en Filipinas.

Me interesa mucho historiografiar estos espacios de frontera en Filipinas y en particular los conflictos que las Órdenes tenían entre sí y también me interesan los espacios de Cabildos Eclesiásticos, como los de Manila -el Cabildo Eclesiástico de Manila me interesa mucho; he hecho algo sobre Cabildos en Perú y también en Manila pero me gustaría hacer un libro sobre Sedes Vacantes. Es decir, esto es una cosa que tengo en mente. Es algo que no se ha trabajado mucho y en Filipinas nada y me parece que se tendría que hacer alguna cosa relacionada con eso. Es decir, responder qué pasa cuando no hay Arzobispo?, quién manda allí? En Filipinas pues las Órdenes tenían mucho poder, incluso se las llamaba la 'frailocracia'. Los Obispos incluso llegaron a ser, algunos de ellos, gobernadores mismos. Cuando el Gobernador no estaba, quién gobernaba era el Arzobispo de Manila. Claro el Arzobispo tenía mucho poder pero las Sedes Vacantes tenían una importancia notable porque el Cabildo sustituía al Arzobispo y creo que eso es lo que tendríamos que explicar para el XVIII.

Ese es el Proyecto de Investigación que voy a desarrollar en los últimos años, explicar cómo funcionaba aquello. Creo que el XVII es importante por muchas razones, por los conflictos con Holanda, por toda la tensión que hay en el ocaso del Imperio español y la aparición de nuevas hegemonías imperiales; me parece que esto es lo que me va a ocupar durante los próximos años.

\footnotetext{
4 Elogio de la Antropología Histórica. Enfoques, métodos y aplicaciones al estudio del poder y del colonialismo. Alexandre Coello de la Rosa y Josep Lluís Mateo Dieste. Zaragoza: Prensas de la Universidad de Zaragoza; Barcelona: Editorial UOC. 2016.
} 
Pregunta: En la formulación que animó nuestro Dossier mencionábamos que "el bagaje conceptual que la Compañía de Jesús desarrolló durante la administración de la política nativa así como desde la formulación de esquemas conceptuales para el diálogo con otras experiencias misionales del orbe, representa una de las aristas necesarias de ser comprendidas para analizar la circulación de saberes sobre realidades nativas particulares". Dentro del problema de la circulación de saberes y conformación de un paradigma etnológico global, qué apuntarías sobre la necesidad de rescate permanente de lo local dentro de esa trama global que conformó la Compañía? Podríamos suponer que los jesuitas americanos realizaron un aporte particular al bagaje conceptual al que hacíamos referencia?

Respuesta: Por mi experiencia lo que puedo señalar, a partir de editar algunas Historias en los últimos años, en particular, por ejemplo, la Historia de las Marianas ${ }^{5}$ de Luis de Morales y de Charles Le Gobien, es que existen, como en el segundo capítulo de ese libro, joyas etnográficas y son muy interesantes de ser abordadas. Creo que la Compañía de Jesús tiene auténticas joyas etnográficas dentro de libros o Historias muchas veces desconocidas. Por ejemplo el libro de Francisco Ignacio Alsina, también para Filipinas que es una obra que no se publicó hasta muy tarde. Fue desconocida por un buen tiempo, o la obra que estoy editando ahora de Diego de Oña que es una obra necesaria de ser conocida -pues de lo que me gustaría hablar ahora en Brasil en las XVII Jornadas Internacionales sobre Misiones Jesuíticas. $^{6}$

Esta es una obra que no se publicó nunca; una obra de más de 1521 páginas que tiene cosas muy interesantes. Hay obras de la Compañía de Jesús, algunas de ellas publicadas, otras no, que contienen toda una serie de elementos muy interesantes -y ahí se hace presente 'lo local'- que deberíamos rescatar porque allí es dónde los autores explican o retratan las vidas de aquellas comunidades. Muchos de ellos eran misioneros o escribían de primera mano. Entonces claro, es difícil hablar de estas obras como etnologías. Yo creo que no lo son pero sí que son etnografías o trabajos etnográficos que son centrales por la descripción que brindan de las vidas de estos grupos étnicos y que son a veces muy detalladas. Entonces yo creo que, en relación a 'lo local', existe todo un acervo que se puede recuperar y esto, entonces, ¿cómo afecta lo global? Pues yo creo que la Compañía de Jesús tenía muy en claro este punto, y esto lo comentaba Jerónimo de Nadal, el Secretario de la Compañía, en aquella famosa frase "nuestro lugar es el mundo". Entonces es claro que la

\footnotetext{
5 History of the Marianas by Fathers Luis de Morales, SJ \& Charles Le Gobien, SJ. Mangilao, Guam, Micronesian Area Research Center \& University of Guam, 2016.

6 XVII Jornadas Internacionales sobre Misiones Jesuíticas "La Acción Global de la Compañía de Jesús: Embajada política y mediación cultural en un escenario mundial"; 22 al 25 de octubre de 2018. UNISINOS. São Leopoldo-RS (Brasil). Allí nuestro entrevistado, el día 23 de octubre, participará de la Mesa Redonda, junto a Eduardo Neumann (UFRGS), Escritas de índios \& escritas de padres: confluências para uma história das missões. Mayores informaciones del evento pueden encontrarse en http://www.unisinos.br/eventos/xviijornadas-internacionais-sobre-as-missoes-jesuiticas-ex123411-00001
} 
Compañía de Jesús quiere abarcarlo todo y lo abarca de muchas formas, desde la escritura, a través de la comprensión de esos grupos a los que quiere evangelizar y, entonces hay toda una serie de trabajos que están, yo creo, muy vinculados a esta etnografía que ellos luego poco a poco van perfeccionando.

En relación a América, pues tu sabes de esto más que yo, para el Chaco, para Paraguay hay muchos ejemplos dónde la Compañía pues hace trabajos detalladísimos de grupos étnicos. Incluso, lo sabemos: llega a "inventarlos" pero también los describe de modo ejemplar aunque también es verdad que algunas veces llega a canonizar ciertas prácticas, ciertas formas de vida que quizás un antropólogo "se tiraría de los pelos". Pero ellos, los jesuitas, también intentan comprender desde su perspectiva aquello que allí acontecía; claro, muchas veces, era una postura eurocéntrica pero de todas maneras es lo que tenemos. Es decir, lo que yo creo que hay que hacer es intentar trabajar pues un poco a contrapelo con esos textos para extraer de ahí lo local dentro de una Compañía cuyo proyecto era netamente global.

Pregunta. El mundo indígena americano, desde lo que conocemos por la historiografía especializada así como por las crónicas jesuíticas devenidas en fuentes modulares, ha demostrado tener una amplia capacidad de adaptación de sus bases y formas sociales de relación con otros nativos así como con no americanos. Dentro de este conjunto de transformaciones podemos aventurar que la circulación de saberes que modeló aquella globalidad impulsó resignificaciones del mundo nativo?

Respuesta: No lo sé, es complicado eso.

[Nota del Editor: Aquí Alex duda y toma un respiro antes de continuar. En este intervalo reformulo la pregunta y hago mención a que en casi todas las Crónicas se hace mención a que los jesuitas son 'los primeros en llegar' a aquel mundo nativo que han de describir pero el mundo indígena americano sabe de ellos desde hace mucho tiempo antes de su llegada]

Continuación de la respuesta: Esto es un poco lo que comentábamos antes. Yo creo que efectivamente hay una visión de que cuando llega el europeo parece que la Historia Indígena empieza y no comienza allí. Es decir esto es un debate que teníamos hace algunos años en el mundo andino. Es decir, ya existían comunidades o reducciones antes de la llegada de los jesuitas como lo señalaba [José María] Arguedas. Lo que sucede es que se van transformando, se van adaptando, y creo que más que los jesuitas inventar al indio, el indio se va re-inventando continuamente a partir de la llegada de estos nuevos grupos. Pero esto es un proceso de lo que siempre hablamos los antropólogos; la cultura se transforma 
continuamente. Entonces claro esto parece un poco de perogrullo. No es que estemos inventando culturas ni tampoco los nativos "inventan" su cultura. Nada se inaugura de cero, la cultura siempre se va transformando, adaptando e incorporando nuevos elementos a lo que ya existe. De manera que es como cuando hablamos hoy en día de lo chamorro. De hecho los chamorro hoy en día se reivindican así mismos como chamorros pero todo el mundo sabe que lo que existe hoy en día como el grupo chamorro en Marianas es producto de una mezcla tan heterogénea dónde alguno diría "pues muy poco chamorro queda" porque el $90 \%$ murió víctima de las epidemias y claro, de lo que estamos hablando es de grupos que vienen de Nueva España, de Filipinas, de las islas Carolinas. Entonces, al final es que uno se tiene que preguntar, y eso es lo importante que no debemos de olvidar, no es tanto si eso es auténtico, si no, cómo el grupo está reivindicando eso como auténtico? Entonces claro, es cierto, nosotros seguimos pensando en el objeto en términos de autenticidad sin importarnos cómo ese grupo se lo apropia y lo utiliza para su propia conveniencia y cómo es que lo resemantiza y creo que eso es lo importante.

Es decir, creo, que el problema está en observar como un antropólogo y mirar como un historiador. Los historiadores queremos ver objetos, ver cosas tangibles. Para los antropólogos pues quizás eso no es lo más importante; lo relevante es ver la cultura en transformación y a mi me parece que eso para la Antropología Histórica es lo más importante. Por ejemplo abordar cuestiones sobre cómo algunas culturas a partir de los siglos XIX y XX y sobre todo como actualmente determinadas etnias se están reinventando. Esto es entonces lo que llamamos ahora como "reinvención cultural". Creo que eso es importante y quizás ahí esté la cuestión de ver cómo estas culturas se van resignificando continuamente y cómo es que así lo hicieron en el pasado.

[Nota del Editor: Aquí hacemos una breve pausa y señalo a Alexandre Coello de la Rosa que en algunas ocasiones percibimos una suerte de esencialismo en algunos de aquellos que trabajan con crónicas jesuíticas. Un esencialismo que contradice esta transformación constante de la cultura]

Continuación de la respuesta: Claro!, igual que cuando hablábamos en Perú que decíamos “...en 1533 cuando llega Pizarro”, “...cuando llegan los españoles a Cajamarca la Historia empieza". Claro que no empieza pero es curioso lo que sucede. Hay allí como una especie de fractura que parece como que lo que hubiese existido antes no es importante. Y claro, yo muchas veces pienso, los españoles que llegaron a Marianas son otros de los muchos grupos que habían llegado antes, porque no fueron los primeros, pero muchas veces la Historia Canónica, Oficial o Imperial piensa aquello como un momento fundacional; la llegada de los españoles es el momento culminante en la historia de "esos pobres salvajes" que eran salvajes hasta que "llegamos nosotros". Creo que ese es el gran problema y claro que eso se hace presente en la Historia jesuítica; cuando estamos editando obras, es siempre la misma 
historia que empieza con la llegada de Legazpi en Manila; porque ese es el gran momento. En 1565, llega López de Legazpi ${ }^{7}$ entonces ahí comienza la historia de las Filipinas y claro, uno se pregunta, y lo que había antes? Antes habían llegado los musulmanes, que luego los expulsaron. Parece como que lo anterior no tuviera importancia pero los jesuitas inventan también esa Historia a partir de la llegada misma de la Compañía de Jesús.

Pregunta: La escritura etnológica generada por la Compañía de Jesús permite contar con un reflejo, condicionado por cierto, tanto de la forma en que la Orden gestionó cómo registrar los eventos acontecidos allende el Viejo Mundo, así como hace posible generar nuevas indagaciones sobre el mundo nativo. Desde tu experiencia de investigación y tus formulaciones sobre la escritura jesuítica así como sobre la Antropología Histórica qué nos podrías apuntar sobre qué caminos deben de explorar las indagaciones sobre la escritura jesuítica? En esta apreciación cómo considerás que incide tu mirada sobre Perú primero y luego sobre Filipinas?

Respuesta: Dejame que te brinde un avance porque esto es lo que quiero exponer en UNISINOS en las XVII Jornadas... pero yo creo que ahora mismo, y antes me preguntabas en lo que estaba metido -y estoy metido en varias cosas. Una de las cuestiones en las que estoy ahora es en la edición de una obra de la Compañía de Jesús que nunca se publicó. De las historias jesuitas de la Compañía de Jesús en Filipinas está la obra de Chirino, está la obra de Francisco Colín, que se llamaba Labor Evangélica; está la obra de Diego de Oña que es la que estamos editando y que se llamaba Labor Evangélica y que nunca se publicó. Esta obra está en Roma y la tenemos aquí; una copia del siglo XIX. La estamos editando ahora y nunca se publicó a pesar que Diego de Oña, que era un misionero jesuita profeso de 4 votos, que estuvo allá, pensaba hacer la tercera parte y todo. Él acaba la obra en 1701. Se la entrega al Rector del Colegio de Manila y por lo visto era tan mala que los evaluadores pusieron "merito quidem". Algo así como decir "no la vamos a publicar ni falta que hace...". Luego está la obra de Pedro Murillo Velarde, que sustituye a esta obra, que publica en 1743 la obra que no se publicó de Diego de Oña - pero 50 años más tarde.

Entonces lo que quiero decir con esto es, para responder a tu pregunta, qué deberíamos de hacer en términos de, por ejemplo, historiografía o de escritura? Pues por ejemplo publicar obras o cosas que la Compañía de Jesús no quiso publicar. Por ejemplo hay un montón de historias que están como estas y, no sólo de Filipinas, que la Compañía no quiso publicar. A mi da la impresión y estoy convencido de ello de que muchas veces es más

\footnotetext{
${ }^{7}$ Nota del Editor. Miguel López de Legazpi fue Gobernador de Filipinas; allí estableció el modelo de encomiendas, utilizado para la América española, para la administración de los naturales, encargando su evangelización a Órdenes religiosas entre las que se debe de contar a la Compañía de Jesús.
} 
ilustrativo lo que no se publica que lo que se publica. Es decir uno aprende mucho indagando lo que no se quiere mostrar. Lo que estamos haciendo ahora es comparar la obra de Diego de Oña con la de Pedro Murillo Velarde que sí se publicó: Historia de las Filipinas. Entonces es muy interesante porque comparando las 2 obras uno entiende por qué la obra de Diego de Oña nunca se publicó. Es decir no sólo porque era el doble de amplia sino porque había muchas cosas que no se podían decir. Ya no sólo desde la composición de lugar sino desde la corrección política. Diego de Oña plantea su obra casi como una Historia de Naufragios, una historia pesimista. Una Historia que si tu le llevas esa historia a un Rector en la Península, pues "es que no reclutas ni a un misionero" [risas] porque era tan pesimista y tan horrible aquello; era "una historia para llorar!" Entonces claro, por qué no nos ponemos a publicar historias de jesuitas de estas que fueron rechazadas o bien por qué no comenzamos a explorarlas para entender un poco el por qué; porque esa es un poco la forma en cómo la Historia crea esa imagen de sí misma.

La Compañía de Jesús crea una imagen de sí misma a partir de lo que se publica pero interesante también es ver lo que no se llega a publicar. Y estas obras existen. Tenemos obras en los archivos desde dónde podríamos rastrear y explorar la otra cara de la Compañía de Jesús, que es la cara que la Orden no quiso que se viera. Muchas veces está ahí, muchas veces hay obras que se aceptan pero hay muchas que no se aceptaron. Entonces sólo comparando las dos caras puedes entender porque esa obra no era interesante para la Compañía de Jesús porque lo que explicaba no correspondía a la imagen que la Compañía de Jesús quería dar. Eso es lo que yo me estoy encontrando en el caso de Diego de Oña, porque realmente es interesantísimo porque Murillo Velarde cuando publica su obra en 1743, no solo reduce la obra de Oña a la mitad sino que además pule muchas de las cosas que Diego de Oña estaba diciendo así en plan de 'los españoles son unos ladrones, hay corrupción'. Todas esas cosas que uno no debería de poner por escrito. Por eso esta pregunta me va bien para exponer y entender cómo la Compañía está inventando cosas pero también para la posteridad.

[Nota del Editor: Aquí hago referencia, en el diálogo, a la idea de 'Secuestro de la Memoria'; una formulación que estamos trabajando en conjunto con Artur Barcelos (FURG) y que postula, en resumidas cuentas, que somos los historiadores los que siempre volvemos sobre los mismos aspectos que los jesuitas indicaron, en su tiempo, como necesarios de ser abordados. De ese modo reificamos constantemente la Historia misma que la Compañía quiso mostrar.]

Continuación de la respuesta: Como historiadores tenemos datos para afirmar esto. Para el caso de Perú tenemos la obra que se editó de Gerónimo Pallas, de principios del siglo XVII, pero es una historia que no se publicó sino hasta hace bien poco. Es una historia que contenía cuestiones que la Compañía de Jesús no quería que se expresaran de ese modo. 
Pues Pallas era un jesuita italiano, en el momento en que llegan un montón de italianos al Perú y claramente había una tensión porque la Compañía de Jesús estaba en un proceso de cambio y se planteaba si había que dedicarse a las misiones de indios o a las misiones de españoles o a la educación y en ese contexto se escribe una obra que nunca se llega a publicar porque no se permitió difundir determinadas críticas que Pallas estaba lanzando. Yo creo que eso se podría trabajar más desde la Historia y la historiografía creada por nosotros los especialistas que nos interesa la Compañía de Jesús. Ver un poco cuestiones historiográficas, como diría Pink Floyd desde el dark side of the Moon, desde el lado oscuro que está oculto. Creo que se podría hacer bastante sobre eso.

Pregunta: Algo más que nos quieras señalar?

Respuesta: Pues sobre la Compañía, me gustaría mucho que hubiera más intercambio entre nosotros los 'jesuitólogos'. A las Jornadas ... les tengo mucho cariño porque estoy en ellas desde aquellas en Buenos Aires en el 2008 y no he faltado nunca; es un congreso por demás importante para la cuestión de las misiones y me da mucho placer saber que desde hace un tiempo estas Jornadas hayan ampliado su enfoque a otras áreas como Asia y África $y$, entonces a partir de ahí creo que se podría intentar internacionalizar más aún estas Jornadas para darles mayor difusión que la que ya tienen. Intentar integrar estas realidades y darles mayor continuidad, saliendo de América y sus realidades, y que esto siga existiendo porque "me preocupa un poco la salud de las Jornadas". Creo que hay mucho trabajo por hacer. A nosotros nos interesa lo colonial pero hay mucha información para lo que sucede luego de la Restauración, para el siglo XIX y, por ejemplo, para Filipinas el papel de la Compañía de Jesús es fundamental. Siempre sostengo que alguien debe de escribir una biografía de Pablo Pastells, SJ; es un personaje indispensable. Tenemos todas sus cartas aquí en el Archivo de Barcelona. Eso es para alguien que desee hacer una Tesis Doctoral o una investigación post-doctoral. Las cartas de Pastelles están en Barcelona; él fue uno de los que ayudó a Astrain en su obra monumental Historia de la Compañía de Jesús. Es un personaje absolutamente indispensable y creo que allí hay mucho trabajo por hacer dentro de la Orden no sólo durante el período colonial sino que también durante el siglo XIX y XX y animaría a los estudiantes a adentrarse en estos mundos.

Hay que poner siempre las obras de la Compañía en su contexto, en realidad como a todas las obras, y entender que el contexto de producción de una Historia tiene que ver con lo que en ese momento es polémico, es debatible, lo que estaba sucediendo y muchas veces se nos escapa esa parte de cuáles son las problemáticas del jesuita que escribe en su mundo. Allí entenderemos muy bien la forma sobre cómo el jesuita redacta o sobre cómo piensa o cómo se autocensura. Creo que hace falta pensar más en esa cuestión histórica que sucede 
alrededor del que escribe y cómo es que lo condiciona esa historia personal a la hora de redactar o de posicionarse frente a determinados problemas. Creo que eso está pasando continuamente y me parece a mi que en el caso de Pastells es evidente en un contexto de un siglo XIX español en dónde hay problemas con Filipinas por su independencia y con los movimientos de liberación nacional y eso "era una olla a presión"; cómo eso está determinando a que Pastells se ponga a copiar una gran cantidad de documentos que copió del Archivo de Indias? Además hay mucha documentación que se salvó porque Filipinas pertenecía a la 'Tarraconense' aquí en Catalunya y esa documentación pasa al Archivo de Sant Cugat primero y luego se reconvierte en el Archivo de Barcelona; por eso es que aquí tenemos tanta documentación sobre Filipinas y claro, Pastells tuvo muchísimo que ver en eso. Incluso hay que remarcar que hay muchas cosas que tenemos aquí que no están en Roma. Es sólo cambiar el foco de la mirada... 